\title{
Adli Nitelikli Göz Yaralanmalarının Değerlendirilmesi
}

\author{
Evaluation of Ocular Trauma in Forensic Medicine \\ ${ }^{1}$ Beycan Doğan, ${ }^{1}$ Tuğrul Kılıboz, ${ }^{2}$ Arif Garbioğlu, ${ }^{1}$ Kenan Karbeyaz , \\ (11) \\ (11) \\ ${ }^{3}$ Haluk Hüseyin Gürsoy
}

${ }^{1}$ Eskişehir Osmangazi Üniversitesi Tip Fakültesi Adli Tıp Anabilim Dalı, Eskișehir Türkiye

${ }^{2}$ Adli Tip Kurumu Eskişehir Şube Müdürlüğü, Eskişehir, Türkiye

${ }^{3}$ Eskișehir Osmangazi Üniversitesi Tip Fakültesi Göz Hastalıkları Anabilim Dalı, Eskişehir, Türkiye

Correspondence:

Kenan KARBEYAZ

Eskişehir Osmangazi Üniversitesi Tıp Fakültesi Adli Tıp Anabilim Dalı, Eskişehir, Türkiye

e-mail:

drkenankarbeyaz@hotmail.com

\section{Özet}

Göz travmaları adli travmatolojide sıkça karşımıza çıkan olgulardır. Göz travmaları kişi ve kurumlar üzerinde yaratacağı sosyal, ekonomik ve psikolojik yük açısındann önem arz etmektedir. Devam edebilecek hukuki sürece esas oluşturacak adli rapoların nesnel verilerle düzenlenmesi, hak kayıplarının önüne geçecek önemli bir faktördür. Çalışmamızda Eskişehir Osmangazi Üniversitesi Hastanesi Adli Tip Anabilim Dalımıza başvuran adli nitelikli göz travma olgularını incelemek ve literatürle paylaşmak amaçlanmıștır. 2017-2019 yılları arasındaki 3 yıllık dönemde Eskișehir Osmangazi Üniversitesi Hastanesi Adli Tıp Anabilim Dalımıza başvuran adli nitelikli göz travmaları retrospektif olarak değerlendirildi. Olgular yaş grupları, cinsiyet, olayın oluş şekli, yaralanmanın niteliği, yarattı̆̆ komplikasyon, yaşamsal tehlike ve işlev zayıflaması veya yitimi yaratıp yaratmadığı yönleriyle değerlendirildi. Veriler SPSS paket istatistik programı aracılığıyla değerlendirildi, ki-kare, pearson ki-kare ve yüzde analizleri yapıldı. Göz yaralanması olan olguların en küçügünün 2, en büyügünün 79 yaşında olduğu, yaş ortalamalarının $34.21 \pm 1.47$ olduğu görüldü. Erkek olguların \%79.7 si etkili eylem sonucu adli nitelikli göz yaralanması yaşarken, kadınlar da bu oran \%75 olarak bulundu. Olguların 15 inde işlev zayıflaması/yitimi olduğu belirlendi. Yaralanma türü ile ișlev zayıflaması/yitimi arasında anlamlı bir farklılık olduğu görüldü. Penetran yaralanmaların \%54.5 inde işlev zayıllaması ya da yitimi olduğu, künt yaralanmalarda ise bu oranın \%4.8 olduğu görüldü. Adli nitelikli göz yaralanmaları sebep olduğu tedavi ve bakıcı masrafları, engellilik hali, psikolojik yük dolayısıyla kiși ve kurumlar için önemlidir. Devam edebilecek hukuki sürece esas oluşturacak adli raporların nesnel ve nitelikli olması için ve kişinin hak kayıplarının önüne geçebilmek adına, göz yaralanmaları göz hastalıkları uzmanları ile adli tıp uzmanlarının multidispliner değerlendirmesi gereken önemli bir adli travmatoloji konusudur.

Anahtar Kelimeler: Göz yaralanması, adli göz travmaları, adli tıp

\section{Abstract}

Ocular traumas are common cases in forensic traumatology practice. Ocular trauma is important in terms of social, economic and psychological burden. Forensic reports with objective data that will form the basis of the legal process that can continue is an important factor to prevent loss of rights. This study aims at reviewing the epidemiology of ocular trauma presenting to Eskisehir Osmangazi University Hospital. This is a retrospective epidemiological study of patients admitted to Eskisehir Osmangazi University Hospital with ocular trauma from 2017 till 2019. Cases were analyzed with respect to age, sex, the way the incident occurred, the complications it caused. And it was evaluated in terms of whether it was life-threatening and whether it caused visual acuity impairment or loss. Spss software was applied to produce the chi-square, pearson chi-square and percentage analyses. Values of $\mathrm{p}<0.05$ were assumed to be statistically significant. The age of cases ranged between $2-79$ and their mean age was $34.21 \pm 1.47$. It was determined that 15 of the cases had impairment/loss of function. There was a significant difference between the type of injury and the impairment/loss of function. $54.5 \%$ of penetrating injuries had functional impairment or loss, while this rate was $4.8 \%$ in blunt injuries. Traumatic ocular injuries are an important issue of forensic traumatology that must be evaluated by ophthalmologists and forensic medicine specialists together in order to prepare objective and qualified forensic reports that will form the basis of the legal process that can continue and to prevent loss of rights.

Keywords: Ocular injuries, judicial ocular injuries, forensic medicine

Received 03.11.2020 Accepted 01.12.2020 Online published 01.12.2020 


\section{Giriş}

Göz yaralanmaları, göz acilleri içinde önemli bir yer tutmakla birlikte aynı zamanda adli tıp açısından da önem arz eder. Hem ceza hem de tazminat hukuku açısından, düzenlenen adli raporlarda, yaralanmanın ağırlık derecesi ile kalıcı nitelikte tam ya da kısmi özür durumunun aydinlatılması gerekir. Çalışmalarda tüm vücut yaralanmalarının \%7'sini, tüm göz hastalıklarının \%10-15'ini göz travmalarının oluşturduğu belirtilmektedir $(1,2)$. Gözler tüm vücut yüzey alanın \% 0,27'sini, yüz bölgesinin \% 4'ünü kaplar buna rağmen travmadan en çok etkilenen organlardan birisidir (3). Göz travmalar1 özellikle gelişmekte olan ülkelerde tek taraflı görme kayıplarının önemli nedenlerinden biridir (1). Epidemiyolojik bir çalışmada, her yı1 yaklaşı 55 milyon göz yaralanması olduğunu belirterek oküler travma sıklığına dikkat çekilmiştir (4).

Görme kaybı sağlık sorunu olmasının yanında sosyal bir engeldir ve yaratacağı tedavi masrafları, bakıcı masrafları, iş gücü kaybı, ruhsal bozukluklar açısından da önemlidir. Araştırmalara göre, ortopedik engel sonrası en çok görülen özür durumunun görme engeli olduğu bildirilmiştir. Görme engelinin \% 25.45 oranla kaza sonrası oluştuğu belirtilmektedir (5).

Adli göz yaralanmalarında devam edebilecek hukuki süreç için adli raporlar önem arz etmektedir. Eşlik edebilecek orbita tavan kırığı ve kafatası kırıklarının, kafa içi kanama, kontüzyon ve laserasyonunun yaşamsal tehlike oluşturacağı bilinmelidir. Göz kapağı ve çevresinde ekimoz, hematom, yüzeyel laserasyonların, konjonktivada subkonjonktival kanama, korneada perforasyona yol açmayan abrazyon ve kontüzyon gibi basit lezyonların basit tıbbi müdahale ile giderilebilecek nitelikte haller olduğu bilinmelidir. Hukuk sistemimizde duyu veya organlardan birinde sürekli işlev zayıflamas1 veya yitimi halleri, neticesi sebebiyle ağırlaşmış yaralama durumunu oluşturmaktadır. İşlev yitimi veya zayıflaması yönüyle değerlendirme yapılırken her gözün ayrı bir duyu organı olarak değerlendirilmesi gerekmektedir (6).
$\mathrm{Bu}$ çalışmada Eskişehir Osmangazi Üniversitesi Hastanesi Adli Tip Anabilim Dalı'na başvuran adli nitelikli göz travma olgularının incelenmesi verilerin literatürle paylaşılması amaçlanmıştır.

\section{Gereç ve Yöntem}

Bu çalışmada 2017-2019 yılları arasında (3 y1l) Eskişehir Osmangazi Üniversitesi Hastanesi Adli Tip Anabilim Dalımıza başvuran adli nitelikli göz travmaları retrospektif olarak değerlendirildi.

Olgular yaş grupları, cinsiyet, olayın oluş şekli, yaralanmanın niteliği, yarattı̆̆ komplikasyon, yaşamsal tehlike ve işlev zayıflaması veya yitimi yaratıp yaratmadığı yönleriyle değerlendirildi. Olguların adli tıbbi değerlendirilmesinde, "Türk Ceza Kanunu'nda tanımlanan yaralama suçlarının adli tıp açısından değerlendirilmesi" kılavuzundan yararlanılmıştır. Veriler SPSS paket istatistik programı aracılığıyla değerlendirildi, ki-kare, pearson ki-kare ve yüzde analizleri yapıldı. $\mathrm{p}<0.05$ istatistiksel olarak anlamlı kabul edilmiştir.

Çalışma, Eskişehir Osmangazi Üniversitesi Tıp Fakültesi Girişimsel Olamayan Klinik Araştırmalar Etik Kurulunun 14.08.2020 tarihli ve 2020-266 sayılı onayı ile yapılmıştır.

\section{Bulgular}

Çalışmanın kapsadığı 3 yıllık dönemde göz yaralanmas1 olan 198 olgu olduğu tespit edildi. 3 y1llık dönemdeki adli travmatolojiyi ilgilendiren 6407 olgudan \% 3,1 kadarında göz yaralanması olduğu tespit edildi.

Göz yaralanması olan olguların en küçüğünün 2 , en büyügünün 79 yaşında olduğu, yaş ortalamalarının $34.21 \pm 1.47$ olduğu, olguların en sık 30 ila 39 yaş grubu arasında olduğu (\%29.3) belirlendi. Olguların \%79.8'inin $(\mathrm{n}=158)$ erkek, \%20.2'sinin $(\mathrm{n}=40)$ kadın olduğu belirlendi.

Cinsiyet ve yaş grubunun dağılımı tablo $1 \mathrm{de}$ sunulmuştur. Yaş grubu ile cinsiyet arasında anlamlı bir ilişki saptanmamıştır. Her iki 
cinsiyette olguların önemli bir kısmı 20 ila 40 yaş arasında toplanmıştır. (p>0.05) (Tablo 1).

Tablo 1. Olguların yaş gruplarının, cinsiyete göre dağılımı

\begin{tabular}{|c|c|c|c|c|c|c|}
\hline \multirow{3}{*}{ Yaş Grubu } & \multicolumn{4}{|c|}{ Cinsiyet } & \multirow{2}{*}{\multicolumn{2}{|c|}{ Toplam }} \\
\hline & \multicolumn{2}{|c|}{ Erkek } & \multicolumn{2}{|c|}{ Kadın } & & \\
\hline & $\mathrm{n}$ & $\%$ & $\mathrm{n}$ & $\%$ & $\mathrm{n}$ & $\%$ \\
\hline $0-18$ & 19 & 12,0 & 3 & 7,5 & 22 & 11,1 \\
\hline $19-29$ & 46 & 29,1 & 9 & 22,5 & 55 & 27,8 \\
\hline 30-39 & 45 & 28,5 & 13 & 32,5 & 58 & 29,3 \\
\hline $40-49$ & 20 & 12,7 & 11 & 27,5 & 31 & 15,6 \\
\hline 50 ve üzeri & 28 & 17,7 & 4 & 10,0 & 32 & 16,2 \\
\hline Toplam & 158 & 100,0 & 40 & 100,0 & 198 & 100,0 \\
\hline
\end{tabular}

Olguların 156'sinın (\% 78,8) etkili eylem sonucu yaralandığı belirlendi. Olay türleri ile cinsiyet arasında anlamlı bir farklılık olmadığ 1 görüldü (Tablo 2, P>0,05). Erkek olguların \% 79,7'sinin $(\mathrm{n}=126)$, kadın olguların \% 75'inin $(\mathrm{n}=30)$ etkili eylem sonucu yaralandığ 1 belirlendi.

Tablo 2. Cinsiyetin olay türlerine göre dağılımı

\begin{tabular}{|c|c|c|c|c|c|c|}
\hline \multirow[b]{3}{*}{ Olay türü } & \multicolumn{4}{|c|}{ Cinsiyet } & \multirow{2}{*}{\multicolumn{2}{|c|}{ Toplam }} \\
\hline & \multicolumn{2}{|c|}{ Erkek } & \multicolumn{2}{|c|}{ Kadın } & & \\
\hline & $\mathrm{n}$ & $\%$ & $\mathrm{n}$ & $\%$ & $\mathrm{n}$ & $\%$ \\
\hline Etkili Eylem & 126 & 79,7 & 30 & 75,0 & 156 & 78,8 \\
\hline Kaza & 32 & 20,3 & 10 & 25,0 & 42 & 21,2 \\
\hline Toplam & 158 & 100,0 & 40 & 100,0 & 198 & 100,0 \\
\hline
\end{tabular}

Olgularımızın 187 sinin künt, 11 inin penetran yaralanma şekilde olduğu, yaralanma şekli ile cinsiyet arasında anlamlı bir ilişki olmadığ 1 belirlendi $(\mathrm{p}>0.05)$. Olguların 15 'inde işlev zayıflamas1/yitimi olduğu belirlendi. Yaralanma türü ile işlev zayıflaması/yitimi arasında anlamlı bir farklılık olduğu görüldü $(\mathrm{p}<0.01)$. Penetran yaralanmaların \%54.5 inde işlev zayıflaması ya da yitimi olduğu, künt yaralanmalarda ise bu oranın $\% 4.8$ olduğu görüldü (Tablo 3).

Tablo 3. Olayın oluş şeklinin ile işlev zayıflığı/yitimi durumuna göre dağılımı

\begin{tabular}{|c|c|c|c|c|c|c|}
\hline \multirow{3}{*}{ İşlev yitimi veya zayıflaması } & \multicolumn{4}{|c|}{ Olayın oluş şekli } & \multirow{2}{*}{\multicolumn{2}{|c|}{ Toplam }} \\
\hline & \multicolumn{2}{|c|}{ Künt } & \multicolumn{2}{|c|}{ Penetran } & & \\
\hline & $\mathrm{n}$ & $\%$ & $\mathrm{n}$ & $\%$ & $\mathrm{n}$ & $\%$ \\
\hline İşlev Yitimi veya Zayıflaması Yok & 178 & 95,2 & 5 & 45,5 & 183 & 92,4 \\
\hline İşlev Yitimi veya Zayıflaması Var & 9 & 4,8 & 6 & 54,5 & 15 & 7,6 \\
\hline Toplam & 187 & 100,0 & 11 & 100,0 & 198 & 100,0 \\
\hline
\end{tabular}

Olguların 98 (\%49.5)'inin basit tıbbi giderilebilir nitelikte olmadığı şeklinde müdahale ile giderilebilir nitelikte olduğu, 100 raporlandığı görüldü. (\%50.5)'ünün ise basit tıbbi müdahale ile 
Göz yaralanması olan 198 olgunun 24'ünde (\%12.1) eşlik eden lezyonların yaşamsal tehlikeye neden olduğu belirlendi.

\section{Tartışma}

Adli travmatolojiyi ilgilendiren yaralanmalarda, olguların çoğunlukla erkek ve genç yaş grubunda oldukları bildirilmiştir (712). Ankara Üniversitesi Tip Fakültesi Adli Tıp Anabilim Dalı'na 7 yıllık dönemde başvuran 1053 olgunun 680'inin (\% 65,5) erkek olduğu, olguların en sık 21-30 yaş grubunda olduğu bildirilmiştir (10). Göz travmaları ile ilgili yapılan epidemiyolojik çalışmalarda da göz travmalarının genellikle erkeleri ilgilendirdiği bildirilmiştir (13-19). Van'da yapılan, göz travmalarının değerlendirildiği bir çalışmada, göz travmasına maruz kalan olguların \% 81,6'sının erkek olduğu ve yaș ortalamasının 18,7 olduğu bildirilmiştir (19). İstanbul'da yapılan çalışmada olguların \% 86,5'inin erkek olduğu, yaş ortalamasının 27,8 olduğu bildirilmiştir (16). Manisa'da acil servise başvuran göz travmalarının değerlendirildiği bir çalışmada olguların \% 74,7'sinin erkek olduğu, olguların en sık $(\% 28,6) 30-39$ yaş grubunda olduğu bildirilmiştir (20). Sunulan çalışmada, Olguların \%79.8'inin $(\mathrm{n}=158)$ erkek, \%20.2'sinin $(n=40)$ kadın olduğu, olguların en sik 30-39 yaş grubunda olduğu ve yaş ortalamasının 34,2 olduğu belirlenmiştir. Travmatik göz yaralanmalarının daha sık genç erkeklerde görülmesi bu kişilerin; daha sik trafikte olmaları, kaza olasılığı yüksek riskli işlerde daha sık olarak çalışmaları, daha sosyal olmaları, dışarıda daha fazla vakit geçirmeleri ve daha sık kavgaya karışmaları ile açıklanabilir.

Olgular, olay türüne göre değerlendirildiğinde, 156 olgunun (\% 78,8) etkili eylem sonucu yaralandığı belirlendi. $\mathrm{Bu}$ oran Çakırer ve arkadaşlarının yaptığ çalışmada \%8,7 olarak bildirilmiştir (16). Göz kliniklerinde yapılan çalışmalarda, göz travmalarının daha s1k olarak düşme, çarpma gibi küçük kazalar olarak bildirilmiştir $(16,17,21)$. Sunulan çalışmada darp sonucu göz yaralanma oranının yüksek çıkması, çalışmanın bir göz kliniğin değil, adli tıp biriminde yapılmış olmasına bağlanmıştır. Darp nedeniyle yaralanan olguların fazla olasının da etkisi ile olguların \% 94,4'ünün $(\mathrm{n}=187)$ künt travma şeklide olmasına neden olmuştur. Göz kliniklerine travma nedeniyle gelen tüm olgular adli vaka olmayabilir. Ancak göz hekimleri de, diğer tüm hekimler ve sağlık çalışanları gibi, suç ile karşılaştıklarında bunu bildirmek ile yükümlüdürler. Göz travması olan olgular, adli olgu açısından değerlendirilmeli, adli vaka oldukları anlaşılırsa ve daha önce bildirimi yapılmamışsa ilgili kolluk kuvvetlerine gerekli bildirim yapılmalıdır (22). Olay türü ile cinsiyet arasinda anlamlı bir farklılık bulunmadığ 1 belirlenmiştir (Tablo 2, $\quad \mathrm{P}>0,05)$. Olguların çoğunluğu erkek olmakla birlikte $(\% 78,8)$ olay türleri arasında farklı1ık bulunmaması, kadına yönelik şiddet olgularının artması ile açıklanabilir.

Adli raporlarda aydınlatılması gereken konulardan birisi de yaralanmanın işlev

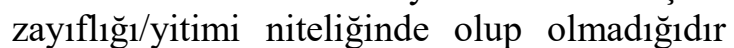
$(6,23)$. Sunulan çalışmada, olguların 15 'inde (\% 7,6) işlev zayıflığı/yitimi saptanmıştır. Yaralanma şekli ile, işlev zayıflı̆̆g/yitimi arasında anlamlı bir ilişki olduğu belirlenmiştir (Tablo 3, $\mathrm{P}<0.0001$ ). Penetran yaralanmaların \%54.5 inde işlev zayıflaması ya da yitimi olduğu, künt yaralanmalarda ise bu oranın \%4.8 olduğu saptanmıştır. Yapılan çalışmalarda, penetran yaralanmaların, gözde daha derin dokular etkilediği ve işlevseliği daha fazla etkileyecek yaralanmalara neden olduğu bildirilmiştir (24-26). Tüm travmatik göz yaralanmalarında, yaralanma sonrası, göz fonksiyon kayıları göz hastalıkları uzmanınca değerlendirilerek adli raporlara kaydedilmelidir. Gerekirse tekrarlı muayeneler yapılmalıdır.

Travmatik göz yaralanmaları neden olacağ fonksiyon kayıpları, oluşturacağı tedavi masrafları, bakıc1 giderleri, ruhsal bozukluklar, sürekli özür halleri yönüyle önemlidir. İş kazası, etkili eylem, trafik kazası gibi durumlarda devam edebilecek ceza davaları ve tazminat davaları için esas teşkil edecek adli raporların objektif ve nesnel değerlendirilmiş olması önem taşımaktadır. Göz travmalarının hem akut hem de uzun dönemde oluşablecek komplikasyonları açısından da göz hastalıkları uzmanlarından görüş alınması önemlidir. Göz travmaları tek başlarına yaşamsal tehlike oluşturmazlar. 
Ancak mevcut olabilecek diğer sistem yaralanmaları için de ilgili branşlarla multidisipliner yaklaşım benimsenmelidir.

\section{KAYNAKLAR}

1. Thylefors B. Epidemiological patterns of ocular trauma. Australian and New Zealand Journal of Ophthalmology, 1992; 20: 95-8.

2. Whitcher JP, Srinivasan M, Upadhyay MP. Corneal blindness: a global perspective. Bull World Health Organ. 2001;79.214-21

3. Omolase CO, Omolade EO, Ogunleye OT, Omolase BO, Ihemedu CO, Adeosun OA. Pattern of ocular injuries in owo, Nigeria. Journal of ophthalmic \& vision research, 2011;6, 114.

4. Négrel, AD, Thylefors B. The global impact of eye injuries. Ophthalmic epidemiology, 1998, 5, 143-69.

5. Türkiye özürlüler araştırması, Devlet İstatistik Enstitüsü Başkanlığı. 2002 Yayın no: 2913

6. Balcı Y, Çolak B, Gürpınar K, Anolay NN. Türk Ceza Kanunu'nda tanımlanan yaralama suçlarının adli tıp açısından değerlendirilmesi rehberi. https://www. atk. gov. tr/tckyaralama24-06-19. pdf, Erişim tarihi: 12.10.2020.

7. Güven FMK, Bütün C, Beyaztaş FY, Eren ŞH, Korkmaz İ. Cumhuriyet Üniversitesi Tip Fakültesi Hastanesi'ne başvuran adli olguların değerlendirilmesi. ADÜ Tip Fakültesi Dergisi 2009; 10: $23-8$.

8. Korkmaz T, Kahramansoy N, Erkol Z, Sarıçil F, Kılıç A. (2012). Acil Servise Başvuran Adli Olguların ve Düzenlenen Adli Raporların Değerlendirilmesi. Medical Bulletin of Haseki/Haseki Tip Bulteni, 2012;50:14-20

9. Yavuz MF, Bastürk P, Yavuz MS, Yorulmaz C. Cerrahpaşa Tıp Fakültesi Acil Servisi'ne başvuran adli olguların değerlendirilmesi. Adli Bilimler Dergisi 2002; 2:21-6.

10. Arslan Z, Kutlu O, Cantürk G. Ankara Üniversitesi Tıp Fakültesi Adli Tip Anabilim Dalı'nda 2012-2018 Yılları Arasında Düzenlenen Adli Raporların Retrospektif Olarak Değerlendirilmesi. Adli Bilimler Dergisi, 2020; 19:7-15.

11. Çelikel A, Karbeyaz K, Akkaya H, Asliyüksek H. Adli Tip Şube Müdürlüğü'ne Yansiyan Yanik Olgulari; Eskişehir Deneyimi. Mustafa Kemal Üniversitesi Tip Dergisi, 2012;3, 9-18.

12. Tiraşçı Y, Durmaz U, Altinal A, Bulut K, Özdemir Y, Cengiz D, Uysal C, Gören S. Dicle Üniversitesi Adli Tip Anabilim Dalınca 2012-2015 Y1lları Arasında Düzenlenen Adli Raporların Retrospektif Olarak Değerlendirilmesi. Dicle Tip Dergisi, 2016;43, 424-30.

13. Altıntaş L, Şener MT, Kır MZ, et al. Pattern of open eye injuries in northwest Turkey: a retrospective study. Ulus Travma Acil Cerrahi Derg 17.4 (2011): 334-339.7.

14. Üstündağ $M$, Orak $M$, Güloğlu $C$, Sayhan $M B$, Özhasanekler A. Göz yaralanması sonucu acil servise başvuran hastaların geriye dönük incelenmesi. Türkiye Acil Tip Dergisi, 2007, 7, 647. 